\title{
К ВОПРОСУ ОБ ИЗМЕНЕНИИ ПЕРЕЧНЯ ЗАКОНОДАТЕЛЬНЫХ КРИТЕРИЕВ КЛАССИФИКАЦИИ ЮРИДИЧЕСКИХ ЛИЦ
}

\begin{abstract}
Аннотация: В статье проводится сравнительно-правовой анализ классификаџионных групп юридических лиц как с учетом норм действующего законодательства РФ, так и в свете предстоящих нововведений. Особое внимание автором уделено отличительным признакам некоммерческих и коммерческих корпораций, показаны предпосылки выделения корпоративных отношений в гражданском праве, обосновано изменение перечня законодательных критериев классификации юридических лии.
\end{abstract}

Ключевые слова: виды, некоммерческие организации, корпоращия, имущественные права, неимущественные права, членство, право на участие.

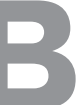

настоящее время в ГК РФ закреплено деление юридических лиц, исходя из соотношения: 1) прав учредителей (участников, членов) и самого юридического лица на имущество последнего (п. п. 2, 3 ст. 48 ГК РФ); 2) цели извлечения прибыли с другими целями деятельности юридических лиц, а также разрешения или запрета распределения полученной прибыли между участниками организации (ст. 50 ГК РФ). Представленные в ГК РФ классификации юридических лиц отражают принципиально важные признаки, являющиеся общими для отдельных их видов. Тем не менее, в юридической литературе неоднократно высказывались точки зрения об отсутствии четкости и достаточности установленных в ГК РФ критериев деления юридических лиц.

Относительно разграничения юридических лиц на коммерческие и некоммерческие основной «порок» критериев кроется в формулировке закона: «Юридическими лицами могут быть организации, преследующие извлечение прибыли в качестве основной цели своей деятельности (коммерческие организации) либо не имеющие извлечение прибыли в качестве такой цели ...». Многие ученые (В. А. Дозорцев, О. П. Кашковский, В. А. Рахмилович) считают, что понятия «основная цель деятельности», «основной вид деятельности» оценочны ${ }^{1}$. Как в ГК РФ, так и в ФЗ от 12.01.1996 № 7-Ф3 (ред. от 28.07.2012) «О некоммерческих организациях» ${ }^{2}$ не содержится признаков, с помощью которых можно было бы отделить основное от неосновного. Этот вопрос осложняется и тем, что

\footnotetext{
${ }^{1}$ См.: Юридические лица: Итоги и перспективы кодификации и совершенствования законодательства. Материалы международной научно-практической конференции // Журнал российского права. - 1998. - № 10/11. С. 43; Рахмилович В. А. О достижениях и просчетах нового ГК РФ // Государство и право. - 1996. - № 4. - С. 123; Кашковский О. П. О критериях разграничения коммерческих и некоммерческих организаций // Юрист. - 2000. - № 5. - С. 14.

${ }^{2}$ Собрание законодательства РФ. - 1996. - № 3.- Ст. 145.
}

любая некоммерческая организация может осуществлять предпринимательскую деятельность, хотя только лишь для достижения поставленных перед нею целей. Причем возможны случаи, когда один и тот же вид деятельности одновременно направлен не только на достижение поставленной перед некоммерческой организацией цели (некоммерческие организации в соответствии с п. 2 ст. 2 Ф3 «О некоммерческих организациях» преследуют цели, направленные на достижение общественных благ), но и на извлечение прибыли. В законодательстве не существует никаких ограничений на возможность получения прибыли от деятельности, направленной на реализацию общественно-полезных целей.

Другим критерием разграничения коммерческих и некоммерческих организаций, который используется в законодательстве РФ, является разрешение или запрет распределения полученной в результате осуществления предпринимательской деятельности прибыли между участниками организации. Согласно п. 1 ст. 50 ГК РФ, п. 1 ст. 2 Ф3 «О некоммерческих организациях» некоммерческие организации не вправе распределять прибыль между ее участниками. В юридической литературе данный критерий рассматривается как позволяющий наиболее четко различать коммерческие и некоммерческие организации. Однако при этом отмечается, что не все некоммерческие организации осуществляют предпринимательскую деятельность, и соответственно получают прибыль, а, значит, ничего не распределяют ${ }^{3}$.

Таким образом, в настоящее время законодательное закрепление критериев деления юридических лиц на коммерческие и некоммерческие не всегда позволяет достаточно точно провести разграничение указанных организаций. В Концепции развития гражданского законодательства РФ, одобренной решением Совета при Президенте РФ

\footnotetext{
${ }^{3}$ См.: Кашковский О. П. Указ. соч. - С. 18.
} 
по кодификации и совершенствованию гражданского законодательства от 09.10.2009 года, доказывается необходимость сохранения деления юридических лиц на коммерческие и некоммерческие, однако предлагается дополнить перечень признаков некоммерческих организаций путем указания на ограниченный (специальный) характер гражданской правоспособности некоммерческих организаций, который распространяется на их право осуществлять предпринимательскую деятельность ${ }^{4}$. В этой связи обосновывается установление в законодательстве правила о включения в устав некоммерческой организации исчерпывающего перечня всех видов разрешенной ей деятельности. Положения названной Концепции нашли свое воплощение в принятом в первом чтении Государственной Думой проекте Ф3 № 47538-6 «О внесении изменений в части первую, вторую, третью и четвертую ГК, а также в отдельные законодательные акты РФ» (далее - проект Ф3

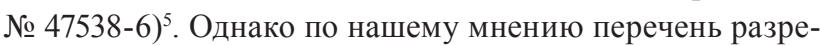
шенных в законе или уставе видов предпринимательской деятельности не решает проблемы критерия соответствия или несоответствия этой деятельности целям создания некоммерческой организации. Для признания организации некоммерческой не имеет значения, какие именно виды деятельности будут осуществляться для достижения поставленных перед нею целей. Главное, чтобы их достижению способствовал любой вид деятельности, ею осуществляемой и не противоречащей требованию закона. Требование к установлению в уставе исчерпывающего перечня видов предпринимательской деятельности неизбежно будет стеснять возможности этих организаций по достижению целей их создания. Поэтому, на наш взгляд, основным критерием разграничения организации на коммерческие и некоммерческие следует считать их основную цель деятельности. Законодатель применительно к делению юридических лиц на коммерческие и некоммерческие «говорит» не о целях деятельности вообще, а об основной, которая и представляет собой реализацию цели создания некоммерческих организаций (согласно п. 2 ст. 2 Ф3 «О некоммерческих организациях» некоммерческие организации могут создаваться для достижения социальных, благотворительных, культурных, образовательных, научных и управленческих целей, в целях охраны здоровья граждан, развития физической культуры и спорта, удовлетворения духовных и иных нематериальных потребностей граждан, защиты прав, законных интересов граждан и организаций, разрешения споров и конфликтов, оказания юридической помощи, а также в иных целях, направленных на достижение общественных благ). Цель,

\footnotetext{
${ }^{4}$ Вестник ВАС РФ. - 2009. - № 11 (Доступ из СПС «КонсультантПлюс»).

${ }^{5}$ Документ опубликован не был (Доступ из СПС «КонсультантПлюс»).
}

ради достижения которой создано юридическое лицо, предопределяет и основную его деятельность. Поэтому следует признать, что основной целью деятельности некоммерческой организации является достижение прежде всего общественных благ. Это означает, что особенностью некоммерческих организаций является удовлетворение в первую очередь нематериальных, духовных потребностей людей и общества в целом. Именно это и определяет детерминирующую роль невозможности или сложности извлечения прибыли. Думается, законодатель исходил из того, что цель создания некоммерческой организации, выражающаяся именно в достижении общественных благ, объективно не может порождать для нее в качестве первостепенной задачи получение прибыли от общественно-полезной деятельности, а это в свою очередь отражается на ее основной цели деятельности.

Другая классификация юридических лиц проводится в ст. 48 ГК РФ и основывается, как нами было ранее отмечено, на критерии соотношения прав учредителей (участников, членов) и самого юридического лица на имущество последнего. Б. М. Гонгало справедливо заметил, что «... в п. п. 2 и 3 ст. 48 ГК РФ содержатся правила, позволяющие определить, имеют ли участники (учредители) юридического лица имущественные права в отношении данного юридического лица, и если «да», то какие это права. И не более того» ${ }^{6}$. Таким образом, закрепленная в п. п. 2 и 3 ст. 48 ГК РФ классификации юридических лиц не дает возможным полностью определить правовую связь юридического лица с его учредителем (участником, членом), поскольку наряду с имущественными правами член организации обладает рядом неимущественных прав, к числу которых следует отнести прежде всего право на участие в юридическом лице. Именно поэтому авторы Концепции развития гражданского законодательства РФ предложили охарактеризовать права участников хозяйственных обществ и товариществ, а также кооперативов в качестве корпоративных прав, имея в виду как «права участия» в юридическом лице, так и соответствующие обязательственные права. Однако введение категории корпоративных прав только в отношении указанных коммерческих организаций, без учета возможности выделения корпоративных прав применительно к некоммерческим организациям было бы не вполне справедливым, отсюда, как нам представляется, Ф3 № 47538-6 не устанавливает ныне закрепленное в п. п. 2 и 3 ст. 48 ГК РФ деление юридических лиц. Вместе с тем подобный подход вовсе не предполагает отказ от категории корпоративных от-

\footnotetext{
${ }^{6}$ Гонгало Б. М. Доля в уставном капитале общества с ограниченной ответственностью как объект гражданского оборота // Проблемы развития частного права: Сборник статей к юбилею Владимира Саурсеевича Ема / отв. ред. Е.А. Суханов, Н.В. Козлова. - М., 2011 (Доступ из СПС «КонсультантПлюс»)
} 


\section{Право и политика $1(157) \cdot 2013$}

ношений в гражданском законодательстве РФ, а также возможности деления юридических лиц на корпорации и унитарные организации. Так, согласно ГК РФ (в редакции проекта Ф3 № 47538-6) к отношениям, регулируемым гражданским законодательством, отнесены и те, которые связаны с участием в корпоративных организациях или с управлением ими (ст. 2), а юридические лица, являющиеся некоммерческими организациями, могут создаваться в одной из организационно-правовых форм некоммерческих корпораций (потребительских кооперативов, общественных организаций, ассоциаций (союзов)) и некоммерческих унитарных организаций (фондов, учреждений, религиозных организаций) (п. 3 ст. 50). Кроме того, ст. 65.1 ГК РФ (в редакции проекта Ф3 № 47538-6) устанавливает понятие корпорации и унитарной организации по признаку наличия или отсутствия права членства (права на участие в управлении деятельности организации) у ее участников (членов) и определяет перечень соответствующих организационно-правовых форм коммерческих и некоммерческих организаций.

Как видим, в ГК РФ (в редакции проекта ФЗ № 47538-6) разграничение юридических лиц на корпорации и унитарные организации по критерию наличия или отсутствия права членства проводится наряду и во взаимосвязи с делением на коммерческие и некоммерческие организации по критериям основной цели деятельности организаций и условий распределения полученной прибыли, что подчеркивает отсутствие полного совпадения правового статуса коммерческой и некоммерческой корпораций. В этой связи представляет интерес высказанная в юридической литературе точка зрения Ю. Н. Андреева, согласно которой если корпорация не занимается предпринимательской деятельностью, ее следует отнести к корпорациям второго уровня (такой вывод ученым был сделан применительно к ассоциациям (союзам $)^{7}$. Однако, на наш взгляд, наличие отношений членства (как основной признак любой корпорации) никак не может зависеть от вида деятельности, которыми может заниматься организация (скорее сам факт наличия членских отношений в организации может отражать связанные с этим виды деятельности). Целью деятельности некоммерческой корпорации является не извлечение прибыли, ее создание обусловлено, как правило, задачами удовлетворения нематериальных потребностей ее участников (членов), которые для достижения этих целей могут делать в пользу корпорации имущественные взносы ${ }^{8}$. Отсюда,

${ }^{7}$ См.: Андреев Ю. Н. Механизм гражданско-правовой защиты. - Норма, Инфра-М, 2010 (Доступ из СПС «КонсультантПлюс»).

${ }^{8}$ См.: Ломакин Д. В. Корпоративные правоотношения: общая теория и практика ее применения в хозяйственных обществах. M., 2008. - C. 80. как нам представляется, различие в правовом статусе некоммерческих и коммерческих корпораций должно проводится несколько в иной плоскости, а именно в выявлении правовой характеристики интересов членов корпораций и, как следствие, в порождаемых согласно их интересам корпоративных правах, составляющих «ядро»их правового статуса.

Анализ норм ст. ст. 6, 8, 12 Ф3 «О некоммерческих организаций» позволяет применительно к правам членов ряда организационно-правовых форм некоммерческих организаций (общественной организации, некоммерческого партнерства, ассоциаций (союзов)) сделать важный вывод о том, что во главу угла их правового статуса поставлены прежде всего их неимущественные интересы и соответственно законодателем акцент сделан на их неимущественных правах, таких как право на участие в управление делами некоммерческой корпорации, получение информации о деятельности некоммерческой корпорации, право избирать и быть избранными в руководящие и контрольно-ревизионный органы, право на добровольный выход из членов корпорации (мы сознательно не ведем речь о таких корпорациях как потребительские кооперативы, поскольку они не вписываются в установленные законодателем признаки некоммерческих организаций). Важно отметить, что ГК РФ (в редакции проекта Ф3 № 47538-6) к числу корпоративных прав членов любой корпорации относит: право на участие в управлении имущественными делами корпорации, право получения информации об имущественной деятельности корпорации, а в случаях, предусмотренных законом или уставом корпорации, право знакомиться с ее бухгалтерской и иной документацией; право обжаловать решения органов корпорации, влекущие гражданско-правовые последствия, в случаях и в порядке, предусмотренных законом; в случаях, предусмотренных законом, право оспаривать совершенные корпорацией сделки и требовать возмещения причиненных корпорации убытков (ст. 65.2). Как видим, речь идет о неимущественных правах членов корпорации (конечно же, в самом проекте подчеркивается возможность иметь и другие права, в том числе имущественные), которые вытекают из такого определяющего (основного) корпоративного права как право на управление, и наполняют его содержание. Однако применительно к перечню дополнительных прав членов некоммерческих корпораций следует подходить с несколько иной «меркой» по сравнению с определением списка прав членов коммерческих корпораций. В числе дополнительных прав членов некоммерческих корпораций несомненно могут быть неимущественные права (например, применительно к правам членов саморегулируемых организаций возможно закрепить в уставе названной организации такие как право их на обучение и повышение квалификации (п. 6 ч. 1 ст. 6 ФЗ от 01.12.2007 
№ 315-Ф3 (ред. от 25.06.2012) «О саморегулируемых организациях $\left.»^{9}\right)$, право на разрешение споров, возникающих между членами саморегулируемой организации, а также между членами названной организации и потребителями произведенных ими товаров (работ, услуг), иными лицами (п. 3 ч. 1 ст. 6 Ф3 «О саморегулируемых организациях») и т.д.).

В то же время вопрос о том, можно ли с помощью установления в уставе дополнительных прав членов некоммерческих корпораций закрепить, например, выбор способа права на определение судьбы права участия в некоммерческой корпорации решается неоднозначно. По общему правилу, член некоммерческой корпорации вправе определить судьбу своего права участия в нем только путем выхода из названной организации. При этом Ф3 «О некоммерческих организациях не содержит прямого указания, равно как и запрета на возможность отчуждения права участия в некоммерческой корпорации третьему лицу. Данная проблема была исследована Н. Н. Пахомовой применительно к некоммерческим партнерствам. Так, ученая отмечает: поскольку в п. 5 ст. Ф3 «О некоммерческих организациях» говорится о том, что члены некоммерческого партнерства могут иметь дополнительные права, предусмотренные учредительными документами партнерства и не противоречащие законодательству, то, значит, если в учредительных документах партнерства за его членами будет закреплено право на отчуждение права участия в партнерстве третьим лицам, такое отчуждение возможно в порядке, установленном учредительными документами ${ }^{10}$. Подобная точка зрения была высказана А. С. Еганян: «Взаимоотношения между учредителями (имеется в виду лично-доверительный характер этих отношений) не могут абсолютным образом влиять на «передаваемость» прав, если иное прямо не предусмотрено учредительными документами. Поэтому в учредительном договоре и уставе может быть предусмотрено как право лица - члена партнерства передавать свои имущественные и личные неимущественные права в отношении созданной некоммерческой организации» ${ }^{11}$. Однако привнесение в практику некоммерческих корпораций права их членов на продажу или иное отчуждение права на участие в их деятельности, на наш взгляд, не будет соответствовать самой сути данных организаций, поскольку в отличие, например, от хозяйственных обществ, участники (члены) которых наделены таким правом, они не рассматриваются законодателем как объединение капитала. Сами же корпоративные права членов хозяйственных обществ являются

\footnotetext{
${ }^{9}$ Собрание законодательства РФ. 2007. - № 49. - Ст. 6076.

${ }^{10}$ См.: Пахомова Н. Н. Цивилистическая теория корпоративных отношений. - Екб., 2005 (Доступ из СПС «КонсультантПлюс»).

${ }^{11}$ См.: Еганян А. С. Некоммерческое партнерство как субъект гражданского права // Гражданское право. - 2008. - № 2. - С. 21
}

средством удовлетворения имущественного интереса, поскольку позволяют, например, акционеру участвовать в контроле и направлении акционерного общества по формированию и определению условий соответствующего имущественного обязательства (права) ${ }^{12}$. Приобретая акцию, акционер имеет определенный имущественный интерес, удовлетворение которого осуществляется посредством наделения акционера имущественными правами требования. Справедливо замечание А. Ю. Бушева относительно того, что неимущественные права акционера (права участия) призваны обеспечивать возникновение и исполнение в отношении акционера имущественных обязанностей акционерного общества ${ }^{13}$. В некоммерческих же организациях имущественный интерес членов вынесен на второй план, поэтому и закрепление правила об отчуждении (продаже) права на участие представляется вряд ли возможным. Если член некоммерческой корпорации и имеет имущественные права, то они призваны «обслуживать» реализацию их неимущественных прав. С точностью наоборот относительно специфики корпоративных прав акционеров высказывается Д. В. Ломакин: «... все неимущественные права участников корпоративных отношений, по сути, призваны «обслуживать» реализацию имущественных прав акционеров и акционерное отношение в целом носит имущественный характер» ${ }^{14}$.

Подтверждает нашу точку зрения о невозможности передачи прав членства в некоммерческих организациях и судебная практика. Например, в постановлении Шестнадцатого арбитражного апелляционного суда от 30.11.2009 № 16АП-2462/09 (1) по делу № А633842/09-С1-34 было указано, что объектом гражданских прав может выступать имущественное право члена некоммерческого партнерства - право на получение части имущества некоммерческого партнерства либо стоимости этого имущества, а не членство (право участия) в некоммерческом партнерстве ${ }^{15}$. Правовой статус участников некоммерческих организаций, основанных на началах членства, исключает возможность передачи кому-либо членства (права участия) в некоммерческих организациях. Такой же подход отражен и в проекте Ф3 № 47538-6, согласно которому в ГК РФ вводятся ст. ст. 117.2, 117.7, запрещающие отчуждать членство в общественной организации, ассоциации (союзе).

Таким образом, установление деления юридических лиц на корпорации и унитарные организации наряду с

\footnotetext{
${ }^{12}$ См.: Бушев А. Ю., Попондопуло В. Ф. О балансе интересов акционеров при консолидации акций // Арбитражные споры. 2004. - № 3 (27). - С. 6.

${ }^{13}$ Цит. по: Бушев А. Ю., Попондопуло В. Ф. Указ. соч. - С. 6.

14 Ломакин Д. В. Акционерное правоотношение: понятие, содержание, субъекты: дис. ...канд. юрид. наук. - М., 1996. - С.12-13

${ }^{15}$ URL: http: www. kad. arbitr.ru (Дата обращения 1 декабря 2012 г.).
} 


\section{Право и политика $1(157) \cdot 2013$}

классификацией юридических лиц на коммерческие и некоммерческие организации позволяет выяснить правовую природу названных организаций не только по признаку наличия или отсутствия в них членства, но и предполагает возможность обозначить особенности корпораций с точки зрения порождаемых ими значимых (первостепенных) корпоративных прав (имущественных или неимущественных). В связи со сказанным следует согласиться с Ю. О. Вербицкой относительно того, что «... с научной же точки зрения новая система юридических лиц от этого гармоничного сочетания различных критериев классификации только выиграет» ${ }^{16}$.

Завершая наше исследование, заметим, что реформирование системы юридических лиц не может не основываться на объективной закономерности развития корпоративных отношений не только с участием коммерческих, но и некоммерческих организаций. Соответственно, изменение в гражданском законодательстве РФ перечня взаимосвязанных друг с другом критериев деления юридических лиц неизбежно, в противном случае «отставание» законодательства от реальности может оказать негативное влияние на эффективное использование института юридического лица и в целом на развитие российской экономики.

\section{Библиография:}

1. Андреев Ю. Н. Механизм гражданско-правовой защиты. - Норма, Инфра-М, 2010.

2. Бушев А. Ю., Попондопуло В. Ф. О балансе интересов акционеров при консолидации акций // Арбитражные споры. - 2004. - № 3 (27).

3. Вербицкая Ю. О. Система некоммерческих организаций в проекте ГК РФ // Закон. -2011. - № 4.

4. Гонгало Б. М. Доля в уставном капитале общества с ограниченной ответственностью как объект гражданского оборота // Проблемы развития частного права: Сборник статей к юбилею Владимира Саурсеевича Ема / отв. ред. Е.А. Суханов, Н.В. Козлова. - М., 2011.

5. Еганян А. С. Некоммерческое партнерство как субъект гражданского права // Гражданское право. - 2008. - № 2 .

6. Кашковский О .П. О критериях разграничения коммерческих и некоммерческих организаций // Юрист. - 2000. - № 5.

7. Ломакин Д. В. Акционерное правоотношение: понятие, содержание, субъекты: дис. ...канд. юрид. наук. - М., 1996.
8. Ломакин Д. В. Корпоративные правоотношения: общая теория и практика ее применения в хозяйственных обществах. - М., 2008.

9. Пахомова Н. Н. Цивилистическая теория корпоративных отношений. - Екб., 2005.

10. Рахмилович В. А. О достижениях и просчетах нового ГК РФ // Государство и право. - 1996. - № 4.

11. Юридические лица: Итоги и перспективы кодификации и совершенствования законодательства. Материалы международной научно-практической конференции // Журнал российского права. - 1998. - № 10/11.

\section{References (transliteration):}

1. Andreev Yu. N. Mekhanizm grazhdansko-pravovoy zashchity. - Norma, Infra-M, 2010.

2. Bushev A. Yu., Popondopulo V. F. O balanse interesov aktsionerov pri konsolidatsii aktsiy // Arbitrazhnye spory. - 2004. - № 3 (27).

3. Verbitskaya Yu. O. Sistema nekommercheskikh organizatsiy v proekte GK RF // Zakon. -2011. - № 4.

4. Gongalo B. M. Dolya v ustavnom kapitale obshchestva s ogranichennoy otvetstvennost'yu kak ob'ekt grazhdanskogo oborota // Problemy razvitiya chastnogo prava: Sbornik statey k yubileyu Vladimira Saurseevicha Ema / otv. red. E.A. Sukhanov, N.V. Kozlova. - M., 2011.

5. Eganyan A. S. Nekommercheskoe partnerstvo kak sub'ekt grazhdanskogo prava // Grazhdanskoe pravo. - 2008. № 2 .

6. Kashkovskiy O .P. O kriteriyakh razgranicheniya kommercheskikh i nekommercheskikh organizatsiy // Yurist. - 2000. - № 5.

7. Lomakin D. V. Aktsionernoe pravootnoshenie: ponyatie, soderzhanie, sub'ekty: dis. ...kand. yurid. nauk. - M., 1996.

8. Lomakin D. V. Korporativnye pravootnosheniya: obshchaya teoriya i praktika ee primeneniya $\mathrm{v}$ khozyaystvennykh obshchestvakh. - M., 2008.

9. Pakhomova N. N. Tsivilisticheskaya teoriya korporativnykh otnosheniy. - Ekb., 2005.

10. Rakhmilovich V. A. O dostizheniyakh i proschetakh novogo GK RF // Gosudarstvo i pravo. - 1996. - № 4.

11. Yuridicheskie litsa: Itogi i perspektivy kodifikatsii i sovershenstvovaniya zakonodatel'stva. Materialy mezhdunarodnoy nauchno-prakticheskoy konferentsii // Zhurnal rossiyskogo prava. - 1998. - № 10/11

${ }^{16}$ Вербицкая Ю. О. Система некоммерческих организаций в проекте ГК РФ // Закон. - 2011. - № 4. - С. 46. 